\title{
Multidisciplinary care for better clinical outcomes: role of pharmacists in medication management
}

\author{
Vivian WY Lee *, PharmD, BCPS (AQ Cardiology), Franco WT Cheng, MClinPharm, BCPS \\ School of Pharmacy, The Chinese University of Hong Kong, Shatin, Hong Kong
}

Hong Kong Med J 2018;24:96-7

*Corresponding author: vivianlee@cuhk.edu.hk

DOI: 10.12809/hkmj175076

\section{Global ageing issue and the situation in Hong Kong}

The global population aged 60 years or older was 962 million in 2017 - double the number in 1980-and is expected to double again by $2050 .{ }^{1}$ More significantly, older persons are expected to outnumber children younger than 10 years and adolescents in 2030 and 2050, respectively. ${ }^{1}$ The ageing population is a global issue and Hong Kong is not exempt. Despite the persistently low fertility rate, it is projected that the dependency ratio, defined as the number of persons aged under 15 years and 65 years or over per 1000 persons aged 15 to 64 years, will increase from 397 in 2016 to 844 in $2066 .{ }^{2}$

A longer life can be an incredibly valuable resource, ${ }^{3}$ provided it is accompanied by good health. ${ }^{4}$ Nonetheless, over $70 \%$ of Hong Kong elderly people have chronic illnesses, ranging from cardiovascular problems to oncological diseases. ${ }^{5}$ It is also estimated that approximately $40 \%$ of the elderly population in Hong Kong take more than five medications every day. ${ }^{6}$ Given the substantial risk of drug-related problems among elderly people, the medication management for elderly patients in Hong Kong needs to be addressed. Hong Kong has a largely governmentbased subsidised health care system, with more than $90 \%$ of secondary and tertiary care provided by physician consultations in the public sector; a general out-patient clinic visit lasts an average of 3 to 5 minutes. ${ }^{7}$ It is difficult to provide adequate counselling and medication review during such a short time. In 2013, The University of Hong Kong conducted a study to analyse the nature of pharmaceutical services for elderly patients in Hong Kong. Although the study identified a number of services related to elderly patients, the lack of solid data concerning medication errors and effectiveness of pharmaceutical services $^{6}$ made it difficult to understand medication management among the group.

Although there has been no formal study of medication management in an elderly population, research has clearly established a strong relationship between polypharmacy and negative clinical consequences, including but not limited to adverse drug reactions, drug-drug interactions, and noncompliance. ${ }^{8}$ Appropriate medication management may minimise drug wastage that also places a significant economic burden on the health care system.

\section{Multidisciplinary team: role of pharmacists}

The Institute of Medicine (IOM) declared that "health care professionals should be educated to deliver patientcentered care as members of an interdisciplinary team". 9 The IOM also stated that patients receive better and safer care when health care professionals work effectively as a team, understanding each other's roles and communicating effectively. ${ }^{9}$ Pharmacists are known to be drug experts and therefore in a good position to prevent drug-related problems, which are a particular risk for the elderly patients. ${ }^{10-12}$ Different reviews have demonstrated the value of pharmacists in improving the overall quality of prescribing and consequently minimising drug-related problems. The outreach programme led by The Chinese University of Hong Kong has also demonstrated that pharmacists could improve blood pressure control and heart failure symptoms in addition to addressing the many drug-related problems faced by the community elderly population. ${ }^{13,14}$ In this issue, Chiu et $\mathrm{al}^{15}$ show that a pharmacist-led medication review programme was one of the important strategies to enhance the safety and quality of prescription among elderly patients in hospital. The study revealed that over half of the subjects were prescribed inappropriate medications. The authors stated that most inappropriate medication use was related to effectiveness, dosage, and directions. It highlighted the impact of a systematic pharmacistled medication review programme on geriatric patients in the hospital setting. The potential cost-savings from avoidance of inappropriate medication use and unscheduled hospital readmission can be significant in the long term. Pharmacists should therefore be more proactive, both directly and collaboratively, in the teams caring for elders in order to optimise pharmacotherapy.

Despite their value, the pharmacist-topopulation ratio in Hong Kong was only 1 per 2774 population in $2016,{ }^{16}$ a ratio that is significantly less than that reported by the World Health Organization $(1 \text { per } 1000)^{17}$ and other upper-middle-income and high-income countries. ${ }^{18}$ The lack of human resources in addition to the lack of government support may explain the underutilisation of clinical pharmacy services in Hong Kong. It was only recently that the government acknowledged the need to strengthen clinical pharmacy services for elderly persons living 
in elderly homes. ${ }^{19}$ Furthermore, many old-age home managers fail to appreciate that the role of the pharmacist extends beyond just dispensing drugs and instead consider employment of nurses or health care assistants to be a higher priority. ${ }^{6}$ Unless there is a more widespread appreciation of the diverse roles of a pharmacist, clinical pharmacy services in Hong Kong will not evolve.

\section{Government policy}

Recently, the government announced the establishment of the Steering Committee on Primary Healthcare Development to develop a blueprint for the sustainable development of primary care services in Hong Kong with an aim to "encourage the public to take precautionary measures against diseases, enhance their capability in self-care and home care, and reduce the demand for hospitalisation". ${ }^{20}$ Although the effect of primary care may not be instant, its impact could be huge in the near future. The latest Thematic Household Survey Report revealed that over $40 \%$ of patients with chronic illnesses are aged 65 years or older. ${ }^{5}$ The health care system and geriatric care in particular cannot be sustained if no changes are made. An English proverb has it that "an ounce of prevention is worth a pound of cure". From now on, our efforts should be directed away from treating the chronically ill to health promotion. This cannot be accomplished without a team that comprises every health care discipline. The government should have a policy that ensures proper utilisation of all health care professionals in the current setting. Implementation of medication safety programmes to ensure provision of quality pharmaceutical care services to high-risk patients is one of the important strategies for sustainable and cost-saving health care management.

\section{Conclusion}

Better clinical outcomes are achieved by effective multidisciplinary care. Pharmacists in both community and hospital sectors are part of this multidisciplinary team. They are equipped with expert drug knowledge to address drug-related problems. The study by Chiu et $\mathrm{al}^{15}$ demonstrates the clinical and economic benefits of a pharmacist-led medication review programme in the hospital setting.

\section{Declaration}

The authors have no conflicts of interest to disclose.

\section{References}

1. World Population Ageing 2017. Highlights. Available from: http:// www.un.org/en/development/desa/population/publications/ pdf/ageing/WPA2017_Highlights.pdf. Accessed 21 Dec 2017.

2. Hong Kong Population Projections 2017-2066. Available from: http://www.statistics.gov.hk/pub/ B1120015072017XXXXB0100.pdf. Accessed 21 Dec 2017.

3. Beard JR, Biggs S, Bloom DE, editors. Global Population
Ageing: Peril or Promise? Global Agenda Council on Ageing Society. Available from: http://demographic-challenge. com/files/downloads/6c59e8722eec82f7ffa0f1158d0f4e59/ ageingbook_010612.pdf. Accessed 3 Jan 2018.

4. World Report on Ageing and Health. Available from: http:// www.who.int/ageing/events/world-report-2015-launch/ en/. Accessed 3 Jan 2018.

5. Census and Statistics Department, Hong Kong SAR Government. Thematic Household Survey Report No. 63. Available from: http://www.statistics.gov.hk/pub/ B11302632017XXXXB0100.pdf. Accessed 21 Dec 2017.

6. Pharmaceutical services of elderly patients in Hong Kong: scoping study to identify and analyse the nature of pharmaceutical services provided to the elderly in Hong Kong. January 2013. Available from: http://www.ps.org.hk/ uploads/files/Pharmaceutical Services of Elderly Patients in Hong Kong.pdf. Accessed 20 Dec 2017.

7. Lee VW, Law S, Chung NK, et al. Effect and sustainability of pharmacy outreach services in elderly adults: a 5-year experience in Hong Kong. J Am Geriatr Soc 2013;61:2242-4.

8. Maher RL, Hanlon JT, Hajjar ER. Clinical consequences of polypharmacy in elderly. Expert Opin Drug Saf 2014;13:57-65.

9. Greiner AC, Knebel E, editors. Institute of Medicine Committee on the Health Professions Education Summit. Health Professions Education: a Bridge to Quality. Washington DC: National Academy Press; 2003.

10. Wiedenmayer K, Summers RS, Mackie CA, Gous AG, Everard M. Developing Pharmacy Practice: a Focus on Patient Care. Handbook, 2006 edition. Available from: http://apps.who.int/medicinedocs/documents/s14094e/ s14094e.pdf. Accessed 21 Dec 2017.

11. Resnick B, Gershowitz SZ. Pharmacists and the Elderly. Merck Manual Professional Edition. Available from: http://www.merckmanuals.com/professional/geriatrics/ provision-of-care-to-the-elderly/pharmacists-and-theelderly. Accessed 21 Dec 2017.

12. Lee J, Alshehri S, Kutbi H, Martin J. Optimizing pharmacotherapy in elderly patients: the role of pharmacists. Integr Pharm Res Pract 2015;4:101-11.

13. Lee VW, Choi LM, Wong WJ, Chung HW, Ng CK, Cheng FW. Pharmacist intervention in the prevention of heart failure for high-risk elderly patients in the community. BMC Cardiovasc Disord 2015;15:178.

14. Lee VW, Yi PT, Kong KW, Chan PK, Kwok FL. Impact of pharmacy outreach services on blood pressure management in the elderly community of Hong Kong. Geriatr Gerontol Int 2013;13:175-81.

15. Chiu PK, Lee AW, See TY, Chan FH. Outcomes of a pharmacist-led medication review programme for hospitalised elderly patients. Hong Kong Med J 2018;24:98106.

16. Health Facts of Hong Kong. Available from: http://www. dh.gov.hk/english/statistics/statistics_hs/files/Health_ Statistics_pamphlet_E.pdf. Accessed 21 Dec 2017.

17. Global Health Observatory (GHO) data. Available from: http:// www.who.int/gho/health_workforce/en/. Accessed 21 Dec 2017.

18. Global Pharmacy Workforce Intelligence: Trends Report. 2015. Available from: http://fip.org/files/fip/ PharmacyEducation/Trends/FIPEd_Trends_report_2015 web_v3.pdf. Accessed 3 Jan 2018.

19. The Chief Executive's 2017 Policy Address. We connect for hope and happiness. Available from: https://www.policyaddress.gov. hk/2017/eng/pdf/PA2017.pdf. Accessed 20 Dec 2017.

20. Government establishes Steering Committee on Primary Healthcare Development. Press release. Available from: http://www.info.gov.hk/gia/general/201711/29/ P2017112900377.htm. Accessed 21 Dec 2017. 